\title{
Attachment styles and interpersonal approach and avoidance goals in everyday couple interactions
}

\author{
KENNETH D. LOCKE \\ University of Idaho
}

\begin{abstract}
Sixty undergraduates at a public university in the northwest United States recorded their approach and avoidance communal (closeness), uncommunal (distance), agentic (assertion), and unagentic (submission) goals during a total of 836 naturalistic interactions with romantic partners. They also completed a self-report measure of attachment style. Secure attachment predicted more approach than avoidance goals, especially agentic goals. Avoidant attachment predicted goals to avoid and not to approach closeness and submission. Anxious attachment predicted more intense and inconsistent goals; for example, anxiety predicted focusing more on avoiding distance yet less on creating closeness and predicted more within-person variability across interactions in goals to approach distance, avoid closeness, avoid assertion, and avoid submission. In sum, the study revealed strong relationships between enduring attachment styles and momentary interpersonal goals in everyday life.
\end{abstract}

Adult attachment theory (e.g., Fraley \& Shaver, 2000; Hazan \& Shaver, 1994; Simpson \& Rholes, 1998) draws on infant attachment theory (e.g., Ainsworth, Blehar, Waters, \& Wall, 1978; Bowlby, 1973, 1982) to explain individual differences in how adults create and sustain satisfying relationships. The theory suggests that interactions with significant others influence our mental models of the self, others, and interpersonal relationships. These mental models, in turn, influence our thoughts, feelings, and actions in subsequent interpersonal situations.

Contemporary models of adult attachment typically conceptualize individual differences in attachment as variations along two continuous dimensions: attachment anxiety and attachment avoidance (e.g., Brennan, Clark, \& Shaver, 1998; Crowell, Fraley, \& Shaver, 1999).

Kenneth D. Locke, Department of Psychology, University of Idaho.

I thank Gwen Mitchell for helping me enter the data. I presented data from this study at the 2007 meeting of the Society for Interpersonal Theory and Research.

Correspondence should be addressed to Kenneth D. Locke, Department of Psychology, University of Idaho, Moscow, ID 83844, e-mail: klocke@uidaho.edu.
Anxiety and avoidance reflect different ways of experiencing and coping with insecurity (Mikulincer \& Shaver, 2003). People prone to attachment anxiety worry that relationship partners will reject them, abandon them, or judge them unworthy of love and care. Their thoughts, feelings, and actions tend to focus on their partner and especially on whether their partner is available and responsive. In contrast, people prone to attachment avoidance feel uncomfortable with closeness and dependency. They harbor pessimistic beliefs about others and relationships. They tend to dismiss the importance of intimacy and interdependence in close relationships and instead assert their independence and self-reliance.

Anxiety and avoidance are independent dimensions; that is, people can be high on both dimensions (often labeled a fearful-avoidant style), low on both (a secure style), high in anxiety but low in avoidance (a preoccupied style), or high in avoidance but low in anxiety (a dismissing style). People with a secure attachment style experience themselves as generally capable and worthy of affection and experience others as generally trustworthy 
and well intentioned. Therefore, they are comfortable with both mutual autonomy and mutual dependency. A secure attachment style is associated with a variety of relationship experiences and outcomes, including greater commitment, trust, intimacy, passion, satisfaction, stability, and longevity (e.g., Davila, Karney, \& Bradbury, 1999; J. A. Feeney, 2002; Levy \& Davis, 1988; Pistole, Clark, \& Tubbs, 1995; Shaver \& Brennan, 1992).

\section{Approach and avoidance motives and interpersonal goals}

The purpose of the present study is to examine whether attachment styles predict interpersonal goals during everyday interactions with romantic partners. I use the term goals rather than motives because motives typically refer to less conscious and more enduring dispositions, whereas the goals typically refer to the type of conscious, concrete, situation-specific wishes and fears assessed in the current study (Brunstein, Schultheiss, \& Grassmann, 1998; Horowitz et al., 2006).

The choice of which interpersonal goals to study was guided by over half a century of theory and research suggesting that much of the variation in observed interpersonal incentives and behaviors can be modeled as variation in the underlying dimensions of agency and communion (for overviews of this literature, see Horowitz et al., 2006; Pincus \& Gurtman, 2006). Therefore, the study specifically examined the following four types of interpersonal goals: communal goals (e.g., closeness), uncommunal goals (e.g., distance), agentic goals (e.g., assertion), and unagentic goals (e.g., submission).

Additionally, evidence is accumulating that the motivational system consists of both an approach (or activation or appetitive) system and an avoidance (or inhibition or aversive) system (for a review, see Carver, Sutton, \& Scheier, 2000). The approach system focuses on cues indicating actual and potential rewards, energizes behavior directed at decreasing the distance between the person and the desired outcomes, and generates positive feelings (such as excitement) associated with impending rewarding experiences. The avoidance system focuses on cues indicating actual and potential costs, energizes behavior directed at increasing the distance between the person and the undesired outcomes, and generates negative feelings (such as anxiety) associated with impending painful experiences.

I conceptualize the approach and avoidance systems as basic motivational systems that are distinct from but expressed through specific goals. For example, performance goals can take the form of approaching success or avoiding failure (Elliot \& Church, 1997). Of greater relevance to the current study, people also vary in their tendencies to approach rewarding interpersonal experiences or avoid punishing interpersonal experiences, and these variations are associated with individual differences in global approach and avoidance tendencies (Gable, 2006). Because of the ubiquity and importance of the distinction between approach and avoidance goals, the current study assessed goals to approach and avoid each cardinal interpersonal position - specifically, to approach or avoid closeness, to approach or avoid distance, to approach or avoid assertion, and to approach or avoid submission.

\section{Attachment and goals}

Although no previous study has examined the influence of attachment styles on these eight basic interpersonal goals, many studies have yielded findings that can help guide our hypotheses. For example, several studies have suggested links between attachment style and approach and avoidance goals. For example, greater attachment anxiety predicts greater self-reported avoidance system activity and greater attachment avoidance predicts less self-reported approach system activity (Meyer, Olivier, \& Roth, 2005). Likewise, a study of performance and achievement goals found that anxious attachment predicted stronger avoidance goals and avoidant attachment predicted weaker approach goals (Elliot \& Reis, 2003). The fact that avoidant persons report less positive and engaged emotions during everyday interactions also suggests weaker interpersonal approach goal (Kafetsios \& Nezlek, 2002; Tidwell, Reis, \& Shaver, 1996). Finally, in a study of social goals, attachment anxiety 
predicted fear of rejection and avoidance goals (Gable, 2006); this study did not assess attachment avoidance. Overall, the previous research suggests associations between attachment anxiety and a more active avoidance system and between attachment avoidance and a less active approach system. Nonetheless, the associations are at best moderate; therefore, it is also critical to consider the type of interpersonal experience being approached or avoided.

Numerous studies have reported associations between attachment style and personality measures that load highly on the dimensions of agency and communion (e.g., Bartholomew \& Horowitz, 1991; Chen \& Mallinckrodt, 2002; Collins \& Read, 1990; Diehl, Elnick, Bourbeau, \& Labouvie-Vief, 1998; Gallo, Smith, \& Ruiz, 2003; Noftle \& Shaver, 2006; Shaver \& Brennan, 1992; Shaver et al., 1996). The most consistent finding was that secure attachment predicted high levels of agency and communion; that is, secure individuals tended to be simultaneously warm and confident. Compared to secure individuals, avoidant individuals tended to be less communal and anxious individuals tended to be less agentic, although the results for anxious individuals were less consistent. Two specific behaviors that presumably reflect communal and unagentic goals are disclosing personal information and accepting social support. Consistent with the research on personality measures, the research suggests that anxious individuals are open to self-disclosure, while avoidant individuals report less self-disclosure and less interest in self-disclosure (Gillath et al., 2006; Kafetsios \& Nezlek, 2002; Mikulincer \& Nachson, 1991) as well as less interest and enjoyment in receiving social support (Campbell, Simpson, Boldry, \& Kashy, 2005; Gillath et al., 2006). These links between attachment and agentic and communal behaviors may not generalize to goals, though, given that goals are not always expressed in behaviors (Horowitz et al., 2006).

Therefore, studies relating attachment directly to interpersonal goals are also essential. In the context of romantic relationships, such research has focused on goals for sexual contact (Davis, Shaver, \& Vernon, 2004; Schachner \& Shaver, 2004). These studies found that attach- ment avoidance was negatively associated with using sex to promote or express intimacy or caring and was positively associated with using sex to manipulate and exert power over a partner as well as reasons extraneous to the relationship, such as self-enhancement and impressing peers. Attachment anxiety predicted many and varied goals for sexuality, including feeling valuable and loved, feeling closeness, giving and receiving nurturance, feeling powerful and getting what one wants from a partner, feeling the partner's power, and sustaining partner commitment. Some of these sundry goals - such as feeling powerful and being nurtured - may conflict with each other. Anxiety predicts experiencing potentially conflicting altruistic and egoistic goals in the context of caregiving as well (B. A. Feeney \& Collins, 2001).

With respect to social goals more generally, stronger attachment avoidance predicts stronger fears of intimacy and wishes for self-reliance, control, and distance in relation to others (Greenfield \& Thelen, 1997; Mikulincer, 1998; Rom \& Mikulincer, 2003). In contrast, stronger attachment anxiety predicts stronger desires for liking, approval, acceptance, and love from others (Pietromonaco \& Barrett, 2006; Rom \& Mikulincer, 2003). In a study of females' imagined responses to a relationship threat, anxious attachment predicted greater emotional distress and impulses to express both engaging (e.g., "confront my boyfriend") and distancing (e.g., "pull away") reactions at the same time; in contrast, avoidant attachment only predicted distancing responses (Meyer et al., 2005). Finally, simply activating the name of someone with whom a participant had felt secure, anxious, or avoidant shortened response times to interpersonal goal words associated with, respectively, secure attachment (e.g., support), anxious attachment (e.g., cling), or avoidant attachment (e.g., withdraw; Gillath et al., 2006). Although the various studies just reviewed did not examine the link between agentic and communal goals and attachment directly, overall they suggest that attachment avoidance is associated with agentic and uncommunal goals, whereas attachment anxiety is associated with communal, unagentic, and potentially opposing goals. 


\section{Within-person variability}

Previous event-contingent diary research found that within-person variability in agentic and communal interpersonal behaviors over time was largely independent of the mean levels of agentic and communal interpersonal behaviors and that personality traits predicted both the mean levels of behavior and behavioral variability (Moskowitz \& Zuroff, 2004). In order to examine whether attachment anxiety and avoidance would predict mean levels of agentic and communal goals as well as the variability in agentic and communal goals over time, the current study assessed interpersonal goals on multiple occasions.

Previous research suggests that more attachment anxiety predicts more inconsistent interpersonal experiences. For example, greater attachment anxiety predicted greater fluctuations over time in perceptions of partner commitment (Arriaga, Reed, Goodfriend, \& Agnew, 2006). Likewise, a diary study of peer interactions found that in interactions with peers of a different gender, greater attachment anxiety predicted greater variability across interactions in levels of disclosure, support, and positive affect (Tidwell et al., 1996). Moreover, anxious persons themselves report that they tend to experience relationship feelings more quickly and intensely than others do (Hazan \& Shaver, 1987).

Anxious persons may have more extreme and variable interpersonal experiences because they tend to magnify the gravity of minor, fleeting, and sometimes meaningless interpersonal events. For example, in one study, anxious persons reported more interpersonal anxiety and self-consciousness when another participant (an attractive other-gender confederate) used the same pen color as they did, apparently because anxious persons interpreted this trivial and ambiguous behavior as meaning that the other participant was interested in developing a closer relationship (Bartz \& Lydon, 2006). In a related study, greater attachment anxiety predicted construing another's offer to share class notes as having more interpersonal meaning and relationship implications (Bartz \& Lydon, 2006). Similarly, a study of everyday interactions with romantic partners found that, compared to nonanxious persons, anxious persons felt more hurt and pessimistic about the relationship after relationship conflicts but felt more optimistic after supportive events (Campbell et al., 2005). Collectively, the preceding results suggest that anxious persons may be more attentive and reactive to (even incidental, transient, and ambiguous) interpersonal events, which contributes to the inconstancy in their thoughts and feelings about themselves, their partner, and their relationship. Because anxious persons experience more variability in their interpersonal beliefs and feelings, I hypothesized that they would therefore experience more variability in their interpersonal goals.

\section{Overview of the study}

The current study sought to build on previous research in four ways. First, the current study attempted to assess a theoretically grounded and comprehensive set of interpersonal goalsnamely, goals to approach or to avoid closeness, distance, assertion, and submission. Consequently, the current study can speak to some issues that are currently unresolved; for example, are anxious persons more clingy because they desire closeness, fear distance, or both? Second, many of the studies that addressed the attachment-goal link employed indirect (e.g., behavioral or implicit) measures of goals. The current study assessed goals directly and explicitly. Third, most previous studies assessed typical or general goals. In order to make the results expressly applicable to romantic partners' real-life experiences, the current study assessed specific goals during partners' naturalistic interactions. To assess everyday goals, the study used an event-contingent self-recording procedure (Reis \& Gable, 2000). Specifically, each time participants interacted with their romantic partner for more than a few minutes, they completed a standardized interaction record that asked them about their goals during the interaction. Fourth, by sampling multiple interactions, the current study-unlike previous goal studies - was able to assess variability in interpersonal goals within persons over time. 
Prior to completing the interaction records, participants completed a standard measure of attachment style. The hypotheses were as follows: In accord with attachment theory, the research reviewed above depicts individuals with greater attachment avoidance as having discomfort with closeness and dependency and possibly weaker interpersonal goals in general. Therefore, I expected greater attachment avoidance to predict weaker closeness and submission goals and perhaps stronger distance and assertion goals as well. In accord with the seminal descriptions of adult attachment styles, the research reviewed above depicts individuals with greater attachment anxiety as having more intense reactions to interpersonal situations and possibly a more active avoidance system. Therefore, I expected greater attachment anxiety to predict stronger goals and especially stronger avoidance goals. Both theory and research depict individuals with greater attachment anxiety as seeking dependency and fearing rejection. Therefore, I expected greater attachment anxiety to predict stronger closeness and submission goals and weaker distance and assertion goals. Additionally, both within and across the studies reviewed above, the responses of anxious persons appeared more inconsistent and mercurial than those of secure and avoidant persons. Therefore, I expected anxious individuals to report a less stable and coherent pattern of interpersonal goals.

\section{Method}

\section{Participants}

Sixty undergraduates (50 women and 10 men, 88.3\% European American, $M=20.5$ years, $S D=3.7$ years) participated in this study for extra credit in psychology classes at the University of Idaho, a public university in the Northwestern United States with approximately 12,000 students. Using a convenience sample was appropriate given that the study's primary purpose was not to produce generalizable point and interval estimates for particular intercepts and slopes but rather to demonstrate the existence of theoretically meaningful relationships between attachment and goals. All participants had been involved in a romantic relationship for at least 1 month. The mean relationship length was 15.3 months $(S D=$ 18.1 months).

\section{Materials}

Experiences in Close Relationships Scale. The Experiences in Close Relationships Scale (ECR; Brennan et al., 1998) is a self-report instrument that contains two 18 -item scales that assess variation in adult attachment anxiety (sample item: "I worry a fair amount about losing my partner") and attachment avoidance (sample item: "I don't feel comfortable opening up to romantic partners"). Participants rated the extent to which each item described their feelings in close relationships in general (not focusing on any one specific relationship) on 1 (not at all accurate) to 7 (very accurate) scales. The ECR has been used in numerous studies and has shown excellent internal reliability and evidence of validity in relation to both other self-report measures and various relationship outcomes (Brennan et al., 1998; Mikulincer \& Shaver, 2003). In the present study, Cronbach's alphas, which measure reliability, were 0.96 for attachment anxiety and 0.93 for attachment avoidance, and the two scales were modestly positively correlated, $r(58)=.37, p<.01$. Anxiety scores $(M=3.47, S D=1.14)$ tended to exceed avoidance scores $(M=2.79, S D=$ 1.28), $t(59)=3.87, p<.01$.

Perceived Relationship Quality Components Inventory. In order to rule out relationship quality as a mediator of any associations between attachment style and interpersonal goals, participants also completed a measure of relationship quality. The short, six-item version of the Perceived Relationship Quality Components Inventory (PRQC; Fletcher, Simpson, \& Thomas, 2000) assessed six components of relationship quality: satisfaction, commitment, intimacy, trust, passion, and love (e.g., "How much do you love your partner?"). Participants rated their current partner and relationship on each item on 1 (not at all) to 7 (extremely) scales. The scale has been used in several studies and has demonstrated good internal reliability and predictive validity. In the present study, the six items were highly intercorrelated (with $r$ s ranging from .47 to .83 ), so 
I averaged the items to create an index of overall perceived relationship quality $(\alpha=.95)$.

Interaction Record. The Interaction Record (IR) first asked participants to "briefly describe the interaction" on two blank lines; the purpose of this item was to make the specific interaction clear and salient in participants' awareness prior to their completing the remaining questions. Next, 24 items asked participants about their goals during the interaction. All the items began with the phrase "While interacting I was aware of wanting to ...." or "While interacting I was aware of wanting him/her to ... " followed by a specific goal. Half the items assessed approach goals and half assessed avoidance goals. The avoidance goals all began with the words avoid or not. The 12 approach items consisted of four scales representing high or low levels of communion or agency: approach closeness, approach distance, approach assertion, and approach submission. The 12 avoidance items also consisted of four scales representing high or low levels of communion or agency: avoid closeness, avoid distance, avoid assertion, and avoid submission. For each goal scale, Table 1 shows the scale items, the scale alpha, and the mean rating (across all participants and interactions). Overall, people were most aware of wanting closeness or influence and were least aware of wanting distance or to avoid closeness. Given that these were interactions with romantic partners, it is reassuring but not surprising that people generally wanted closeness rather than distance.

\section{Procedure}

After completing the ECR and PRQC, we gave the participants 14 interaction records along with detailed instructions. The instructions stated:

Whenever you interact for more than a few minutes with your current romantic partner, please complete one of the attached

Table 1. Items, mean rating, and reliability data for each goal scale

\begin{tabular}{|c|c|c|c|}
\hline Type of goal & $\begin{array}{l}\text { Cronbach } \\
\text { alpha }\end{array}$ & $\begin{array}{l}\text { mean rating } \\
(0-5 \text { scale })\end{array}$ & Scale items \\
\hline Approach closeness & .84 & 3.1 & $\begin{array}{l}\text { Appear warm and sympathetic, express warmth } \\
\text { or understanding, share a bond or connection }\end{array}$ \\
\hline Approach distance & .84 & 1.0 & $\begin{array}{l}\text { Appear detached and unemotional, keep my } \\
\text { thoughts or feelings to myself, he/she mind } \\
\text { their own business }\end{array}$ \\
\hline Approach assertion & .73 & 2.9 & $\begin{array}{l}\text { Express my views or suggestions, get him/her } \\
\text { to do something, he/she respect my views } \\
\text { or suggestions }\end{array}$ \\
\hline Approach submission & .73 & 2.2 & $\begin{array}{l}\text { Express my willingness to do what he/she } \\
\text { wanted, meet his/her expectations, he/she } \\
\text { make the decisions }\end{array}$ \\
\hline Avoid distance & .70 & 2.5 & $\begin{array}{l}\text { Not feel distant or disconnected, not feel } \\
\text { embarrassed or rejected, he/she not withdraw } \\
\text { or withhold from me }\end{array}$ \\
\hline Avoid closeness & .82 & 1.1 & $\begin{array}{l}\text { Avoid opening myself up too much, avoid } \\
\text { appearing like I really cared, he/she not get } \\
\text { too close or open with me }\end{array}$ \\
\hline Avoid submission & .79 & 1.8 & $\begin{array}{l}\text { Avoid losing or being inferior, avoid appearing } \\
\text { weak or incompetent, he/she not tell } \\
\text { me what to do }\end{array}$ \\
\hline Avoid assertion & .79 & 2.0 & $\begin{array}{l}\text { Avoid an argument, avoid appearing difficult } \\
\text { or stubborn, he/she not get upset or angry }\end{array}$ \\
\hline
\end{tabular}

Note. $N=60$. 
Interaction Record sheets. The record sheet will ask you to describe the interaction in words and then describe (by circling numbers from 0 to 5 on a series of rating scales) what your goals were - that is, what you were aware of wanting - during the interaction. Although you may not always be able to complete the Interaction Record immediately, please try to get to it as soon as possible . . . . Please complete all of the sheets. It does not matter whether you take one day or two weeks to complete the 14 record sheets.

After completing all 14 records, the participants inserted the packet into a slot in a laboratory door. The average time to complete the records was 15.5 days $(S D=10.4$ days). Four participants returned only 13 records; thus, the total number of interaction records collected was 836 .

\section{Results}

Missing data for ECR, PRQC, or IR items were replaced with the grand mean for that item. All the analyses were multiple regression analyses in which the predictor variables were attachment anxiety (standardized), attachment avoidance (standardized), and the multiplicative interaction of Anxiety $\times$ Avoidance. To facilitate interpretation, I standardized the outcome variables across participants.

\section{Did attachment predict goals?}

To test if attachment style predicts goal strength in general, I regressed attachment style on each participant's mean rating across all 24 goals. Greater attachment anxiety predicted higher ratings ( $b=.41, S E=0.13, p<$ $.01, s r^{2}=.14$ ). (The $s r^{2}$, or squared semipartial correlation, shows the percentage of variance in the outcome variable uniquely explained by that predictor variable while controlling for the other predictors in the equation.) The effects of avoidance and the Avoidance $\times$ Anxiety interaction were not significant $\left(p \mathrm{~s}>.4, s r^{2} \mathrm{~s}<.01\right)$. Thus, more anxious individuals reported experiencing stronger goals during interactions.

To control for these differences in overall response elevation, I used the procedure rec- ommended by Moskowitz and Zuroff (2004). For each interaction record, I computed the mean response across all 24 items and then subtracted that mean response from each of the 24 individual responses. These "ipsatized" scores reveal which goals were relatively high or low during the interaction. For example, imagine during a particular interaction, the mean approach closeness rating is 5 for Person A and 3 for Person B; that is, Person A reports stronger approach closeness goals than Person B. Further examination reveals that the mean rating across all goals (avoid closeness, approach distance, etc.) is 4 for Person A and 2 for Person B; that is, Person A reports stronger goals in general. Thus, the ipsatized approach closeness score for both Persons A and $\mathrm{B}$ is +1 . They place the same relative importance on approaching closeness compared to other interpersonal goals. To control for differences in overall response strength, I conducted the subsequent analyses on these ipsatized scores.

To test if attachment style predicted interpersonal goals, I first computed the average score (across the 13 or 14 interactions) for each goal scale for each participant and then regressed attachment style on each of these eight goals. The upper half of Table 2 shows the results. ${ }^{1}$ Attachment avoidance predicted weaker goals to approach closeness and

1. Although hierarchical linear modeling (HLM) is often used to analyze records nested within participants, because the current study analyzed only between-participant variables and required participants to complete the same number of records, ordinary least squares regression (OLS) was an appropriate analytic method. To confirm that this was true, I used HLM (using the program HLM 6.0; Bryk, Raudenbush, \& Congdon, $2005)$ to estimate the 24 "mean goal" coefficients shown in the top half of Table 2. The mean absolute difference in the $t$ values produced by HLM versus OLS was only $0.037(S D=0.034)$. The bottom line shows HLM and OLS yielded, for all practical purposes, identical results. Nonetheless, HLM is a convenient way to estimate the percentage of between-subjects variance in an outcome variable. Fitting unconditional HLM models to the current data revealed a significant percentage of between-subjects variance in all goals (ranging from $24 \%$ for approaching submission to $45 \%$ for avoiding closeness, all $p \mathrm{~s}<.001$ ). The existence of substantial between-subjects variance in goals provides reassurance that studying between-subjects predictors of goals is a meaningful and potentially productive avenue of investigation. 
Table 2. Regression of avoidance, anxiety, and Avoidance $\times$ Anxiety on within-subject means and variances for each type of goal

\begin{tabular}{|c|c|c|c|c|c|c|c|c|c|}
\hline \multirow[b]{2}{*}{ Outcome (goal) variable } & \multicolumn{3}{|c|}{ Avoidance } & \multicolumn{3}{|c|}{ Anxiety } & \multicolumn{3}{|c|}{ Anxiety $\times$ Avoidance } \\
\hline & $\beta$ & $S E$ & $s r^{2}$ & $\beta$ & $S E$ & $s r^{2}$ & $\beta$ & $S E$ & $s r^{2}$ \\
\hline \multicolumn{10}{|l|}{ Means } \\
\hline Approach closeness & $-.25^{*}$ & 0.13 & .05 & $-.31^{*}$ & 0.13 & .08 & .05 & 0.12 & .00 \\
\hline Approach distance & .17 & 0.14 & .02 & -.17 & 0.14 & .02 & -.14 & 0.13 & .02 \\
\hline Approach assertion & -.13 & 0.13 & .02 & -.15 & 0.13 & .02 & $.38^{* *}$ & 0.12 & .14 \\
\hline Approach submission & $-.23 \dagger$ & 0.14 & .05 & -.06 & 0.14 & .00 & .14 & 0.13 & .02 \\
\hline Avoid closeness & $.37 * *$ & 0.13 & .12 & -.14 & 0.14 & .02 & -.08 & 0.13 & .01 \\
\hline Avoid distance & -.13 & 0.13 & .01 & $.39 * *$ & 0.13 & .13 & .02 & 0.13 & .00 \\
\hline Avoid assertion & -.05 & 0.14 & .00 & .17 & 0.14 & .02 & $-.29 *$ & 0.13 & .08 \\
\hline Avoid submiss & $.22 \dagger$ & 0.13 & .04 & $.29 *$ & 0.13 & .07 & -.05 & 0.12 & .00 \\
\hline \multicolumn{10}{|l|}{ Variances } \\
\hline Approach closeness & .01 & 0.14 & .00 & .06 & 0.14 & .00 & .04 & 0.13 & .00 \\
\hline Approach distance & .00 & 0.13 & .00 & $.43 * *$ & 0.13 & .16 & -.06 & 0.12 & .00 \\
\hline Approach assertion & -.19 & 0.14 & .03 & -.08 & 0.14 & .01 & -.05 & 0.13 & .00 \\
\hline Approach submission & -.05 & 0.14 & .00 & .17 & 0.14 & .02 & .08 & 0.13 & .01 \\
\hline Avoid closeness & .14 & 0.13 & .02 & $.31^{*}$ & 0.13 & .08 & -.12 & 0.12 & .01 \\
\hline Avoid distance & .03 & 0.14 & .00 & .21 & 0.14 & .04 & -.04 & 0.13 & .00 \\
\hline Avoid assertion & .04 & 0.14 & .00 & $.26 \dagger$ & 0.14 & .06 & -.03 & 0.13 & .00 \\
\hline Avoid submission & .03 & 0.13 & .00 & $.39 * *$ & 0.13 & .13 & -.12 & 0.12 & .01 \\
\hline
\end{tabular}

Note. $N=60$. Outcome variables are means and variances computed across each participant's 13 or 14 interactions. All predictors and outcomes were standardized except the Anxiety $\times$ Avoidance interaction term.

$\dagger p<.10 .{ }^{*} p<.05 . * * p<.01$.

submission and stronger goals to avoid closeness and submission. Attachment anxiety predicted weaker goals to approach closeness and stronger goals to avoid submission and distance. These results suggest that insecure attachment might predict being generally more focused on avoidance relative to approach goals. To test this possibility, I regressed attachment style on the average of the four avoidance goals (which, being ipsatized scores, is the inverse of the mean of the four approach goals). The tendency to be more focused on avoidance than approach goals was related strongly to attachment anxiety ( $b=$ $\left..11, S E=0.04, p<.01, s r^{2}=.21\right)$ and marginally to attachment avoidance $(b=.07, S E$ $=0.04, p<.1, s r^{2}=.13$ ).

The final columns of Table 2 show that the multiplicative interaction of Anxiety $\times$ Avoidance predicted the goals to approach and avoid assertion. Simple slope analyses (Aiken \& West, 1991) showed that anxiety moderated the effects of low avoidance $(\beta \mathrm{s}=-.56$ and .48 for approaching and avoiding assertion, respectively), $t(56) \mathrm{s}=-3.25$ and $2.63, p \mathrm{~s} \leq$ .01 , but not the effects of high avoidance $(\beta \mathrm{s}=$ .26 and $-.14, t \mathrm{~s}=1.38$ and -0.70 ). Figures 1 and 2 display the predicted means at $1 S D$ above and below the mean on anxiety and avoidance. The figures show the goal to approach assertion was most prominent among secure people and least prominent among preoccupied people; conversely, the goal to avoid assertion was most prominent among preoccupied people and least prominent among secure people.

\section{Within-person variability}

To assess goal variability within persons over time, I computed the standard deviation of each IR item for each participant across his or her 13 or 14 interactions. Then, I regressed attachment style on the mean variability in 


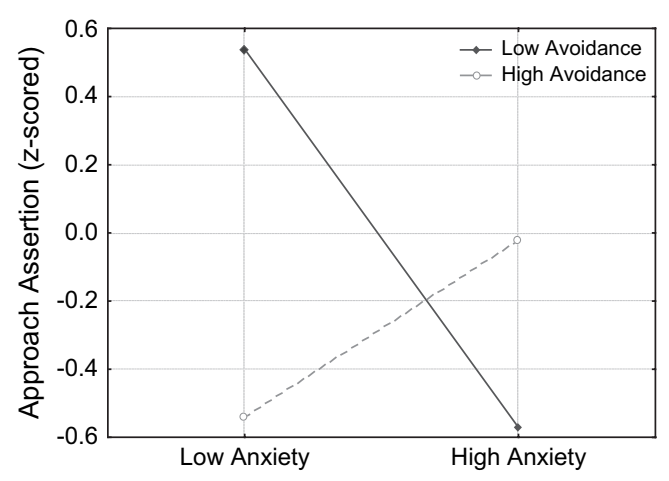

Figure 1. Approach assertion goals as a function of attachment style.

Note. Predicted means are shown at $1 S D$ above and below the mean on attachment anxiety and avoidance.

each of the eight goal scales. The lower half of Table 2 shows the results. Anxiety predicted more variability in goals to approach distance, avoid closeness, avoid assertion, and avoid submission. Neither avoidance nor the Avoidance $\times$ Anxiety interaction predicted goal variability.

Previous studies testing for predictors of variability sometimes control for the effects of the mean and quadratic mean in order to control for possible floor or ceiling effects on variability (Moskowitz \& Zuroff, 2004). Entering the mean and quadratic mean prior to testing the effect of attachment style did

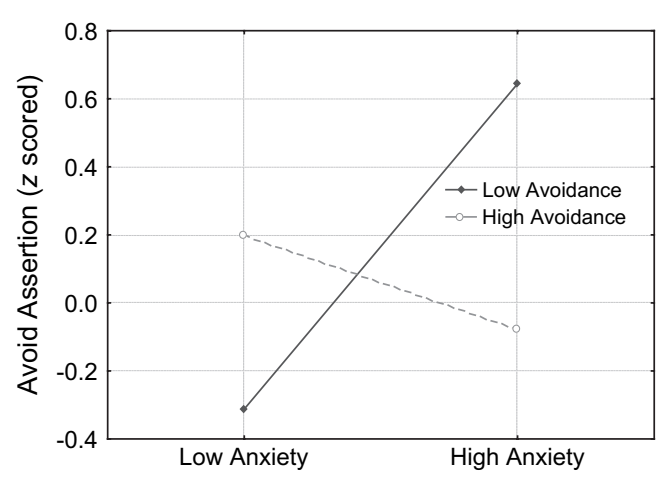

Figure 2. Avoid assertion goals as a function of attachment style.

Note. Predicted means are shown at $1 S D$ above and below the mean on attachment anxiety and avoidance. not alter the pattern of findings but did alter their magnitude as follows: for anxiety on variability in wanting distance $(b=.39, S E=$ $\left.0.14, p<.01, s r^{2}=.19\right)$, for anxiety on variability in avoiding closeness $(b=.25, S E=$ $\left.0.13, p<.1, s r^{2}=.14\right)$, for anxiety on variability in avoiding assertion $(b=.21, S E=$ $0.14, p<.15, s r^{2}=.07$ ), and for anxiety on variability in avoiding submission $(b=.29$, $\left.S E=0.13, p<.05, s r^{2}=.17\right)$. As before, no other effects were significant.

\section{Alternative explanations}

Finally, I regressed attachment style on relationship quality (standardized PRQC scores), relationship length (in months), and age (in years) in order to explore whether the effects of attachment style might be due to variance it shares with these variables. Only two effects were significant: Attachment avoidance was negatively related to relationship length ( $b=$ $\left.-.32, S E=0.13, p<.05, s r^{2}=.09\right)$ and relationship quality $(b=-.49, S E=0.12$, $\left.p<.01, s r^{2}=.20\right)$. Thus, relationship length and quality were unrelated to anxiety or the Anxiety $\times$ Avoidance interaction, and age was unrelated to any attachment style (all $p \mathrm{~s}$ $>$.1). Moreover, age, relationship quality, and relationship length were not significantly correlated with any measures of goals or goal variability tested in the preceding sections with two exceptions: there was a positive association between relationship length and approaching closeness, $r(58)=.27, p<.05$, and a marginal negative association between relationship quality and avoiding closeness, $r(58)=-.24, p=$ .06 . Therefore, age, relationship quality, and relationship length are unlikely to explain the associations between attachment style and goals and, indeed, including them as covariates did not significantly change any of the results reported above. Finally, gender and the time to complete the records also were unrelated to attachment style, goals, or goal variability.

\section{Discussion}

The current study asked individuals to record what they were wanting during everyday interactions with their romantic partners and found 
that global attachment styles predicted these momentary goals. The following sections discuss these findings as well as potential implications, limitations, and future directions.

\section{Attachment, approach goals, and avoidance goals}

As hypothesized, individuals with greater attachment anxiety reported stronger goals while interacting with their partners. If experiencing both strong approach and strong avoidance goals increases the likelihood of experiencing strong approach-avoidance (as well as approach-approach and avoidanceavoidance) conflicts, then anxious individuals may be particularly vulnerable to motivational conflicts, which may contribute to both intrapersonal tension and interpersonal confusion.

People generally reported stronger approach than avoidance goals, but this tendency was less true of insecure individuals, especially those high in attachment anxiety. As noted earlier, prior studies have observed similar connections between attachment anxiety and stronger avoidance goals and between attachment avoidance and weaker approach goals (e.g., Gable, 2006; Meyer et al., 2005).

Overall, the evidence suggests that the attachment system and the motivational system are related to each other, with secure attachment being associated with experiencing more approach than avoidance goals. Precisely how these two systems are interconnected, though, remains an important topic for future research. One possibility is that the attachment system influences the development of the motivational system. Children with more secure attachment relationships may tend to develop more active approach motivation systems because they have more frequent or consistent rewarding experiences, whereas children with more insecure attachment relationships may tend to develop more active avoidance motivation systems because they have more frequent or unpredictable aversive experiences. Another possibility is that the motivational system influences the development of the attachment system. Children with more active avoidance motivation systems may tend to develop insecure attachment styles because they are more attentive to and reactive to punishing interpersonal experiences, whereas children with more active approach motivation systems may tend to develop secure attachment styles because they are more attentive to and reactive to rewarding interpersonal experiences. A third possibility is that the attachment system and the motivational system are partially overlapping, with shared genes or neurological structures influencing both systems. These are not exclusive possibilities and these two systems are likely to be dynamically shaping each other throughout life.

\section{Attachment and agentic goals}

Attachment and assertion. I had hypothesized that assertion goals would be correlated negatively with attachment anxiety and positively with attachment avoidance, and the results were generally supportive. Preoccupied people (high in anxiety but low in avoidance) tended to be the least desirous of and most avoidant of assertion (e.g., were more concerned about not upsetting their partners than about expressing themselves). Conversely, secure people tended to be the most desirous of and the least avoidant of assertion (e.g., were more focused on being heard than on avoiding conflict). Other studies have also found that an anxious (though not necessarily preoccupied) attachment style is associated with a more inhibited and less assertive communication style (e.g., Anders \& Tucker, 2000; Davis et al., 2006). Presumably, when considering whether to say something, preoccupied individuals consider how it might disrupt the relationship, whereas secure individuals consider how it might enhance the relationship. Perhaps secure individuals' confidence that assertion will cause at most momentary tensions is justified given the evidence that secure individuals do express and assert themselves more effectively during potentially conflictual interactions (Corcoran \& Mallinckrodt, 2000; Creasey \& HessonMcInnis, 2001). Interestingly, individuals high in both anxiety and avoidance tended to be more desirous and less avoidant of assertion than were other insecure individuals, perhaps 
because they were simultaneously more concerned about communication than were individuals only high in avoidance but less worried about rejection than were individuals only high in anxiety.

Attachment and submission. I had hypothesized that submission goals would be correlated positively with attachment anxiety and negatively with attachment avoidance. As expected, greater attachment avoidance predicted not wanting to approach submission and instead wanting to avoid submission. While these associations were only marginally significant, they are worth noting because the approach and avoidance goals were consistent both with each other and with theoretical expectations.

Unexpectedly, attachment anxiety also predicted wanting to avoid submission. A possible explanation of this finding is that anxious people - particularly preoccupied people (Henderson, Bartholomew, Trinke, \& Kwong, 2005) - are more likely to experience relationships or interactions in which they are controlled, undermined, or subjected to physical or psychological abuse. Because anxiety predicted avoiding submission and preoccupation predicted avoiding assertion, anxious (or at least preoccupied) individuals may be prone to experiencing avoidance-avoidance conflicts with respect to agency: both fearing to be too assertive (and thereby provoking hostile reactions from their partner) and fearing to be too weak (and thereby vulnerable to hostile behavior from their partner).

\section{Attachment and communal goals}

Attachment avoidance correlated most strongly with the goal to avoid closeness and attachment anxiety correlated most strongly with the goal to avoid distance. I expected these results because discomfort with closeness is a core feature of the construct of attachment avoidance and fear of separation is a core feature of the construct of attachment anxiety. Also unsurprising was the negative relationship between attachment avoidance and wanting to approach closeness, as this also follows from a discomfort with closeness.
The finding that did not fit the hypotheses was that there was also a negative relationship between attachment anxiety and wanting to approach closeness. To understand this unexpected finding, note that attachment anxiety did not predict raw (unipsatized) approach closeness scores. Thus, anxious people were not less desirous of closeness than were other people in an absolute sense, and since most people want closeness (Table 1), that means anxious people want closeness too. Nonetheless, because there were other (viz. avoidance) goals that were also important to anxious people, seeking closeness was relatively less important to them than it was to other people. In other words, because anxious people pay more attention to the goals of avoiding rejection and humiliation, they give relatively less attention to the goals of expressing warmth and sharing intimacy.

\section{Attachment and goal consistency}

As hypothesized, attachment anxiety predicted less consistent goals. Anxiety predicted more variability specifically in approaching distance, avoiding confrontation, avoiding closeness, and avoiding submission. These four goals describe a person desiring to remove or at least protect the self from a potentially punishing relationship situation. The impulse to withdraw evident in these goals was not a chronic impulse. Goal consistency and mean goal intensity were distinct variables; indeed, wanting to avoid distance was on average the strongest correlate of anxiety. Therefore, these self-protective goals were probably specific to certain situations, presumably situations in which the anxious person felt threatened. Future research is needed to clarify what triggers such goals. One possibility is that anxious and nonanxious individuals are sensitive to different types of interpersonal threats; for example, even communal overtures can make anxious individuals feel apprehensive and insecure (Bartz \& Lydon, 2006). Another possibility is that the same types of situations threaten anxious and nonanxious individuals, but anxious individuals have more negative interpretations of relationship events (Collins, 1996; Collins \& 
Feeney, 2004) or have lower thresholds for becoming self-protective.

Fishbach, Friedman, and Kruglanski (2003) suggest another possibility; they found that situation-specific temptations (e.g., to eat) activated competing long-term goals (e.g., to diet), which in turn inhibited the short-term temptations. This was especially true of people who reported being effective self-regulators in that domain (e.g., dieting). Applying these findings to the goals mentioned in the previous paragraph, a temptation to withdraw from a threatening interaction may (due to many prior experiences successfully overcoming that temptation) automatically strengthen a long-term goal to avoid distance, which in turn inhibits the goal to withdraw. In anxious individuals (who may lack a history of successful self-regulation in this domain), the momentary goal to withdraw may often fail to strengthen the enduring goal to avoid distance and, likewise, the enduring goal to avoid distance may often fail to inhibit the momentary goal to withdraw. More generally, situations may activate the same short-term goals in anxious and nonanxious people, but in anxious people those short-term goals may be more often expressed.

The responses of anxious individuals were less consistent not only across time but also across goals. For example, anxiety predicted focusing more on avoiding distance but less on enhancing closeness. To quote another study's similar conclusions: "The effects of anxious attachment, then, appeared to be relatively strong in magnitude but not particularly specific" (Meyer et al., 2005, p. 161). In contrast, the goals of avoidant individuals were more coherent: attachment avoidance predicted not approaching and, instead, avoiding closeness and submission. In sum, the interpersonal vectors of avoidant individuals tended to be agentic and uncommunal. Avoidant individuals may not be personable, but they were predictable.

The impressive internal consistency of the ECR anxiety scale suggests that the complexity of the findings for attachment anxiety cannot be dismissed as due to the anxiety measure being unreliable or multidimensional. Instead, attachment anxiety appears to be a unitary trait with complex motivational consequences (Davis et al., 2004; B. C. Feeney \& Collins, 2001). Even in interviews, anxious people tend to present less coherent, integrated, internally consistent portrayals of their experiences, and feelings in close relationships (Bartholomew \& Horowitz, 1991). An interesting question is whether the partners of anxious individuals also find them difficult to characterize. If so, what is the impact of having a partner whose reactions are difficult to predict and understand? For example, the partners of some anxious individuals may initially become vigilant and careful, but then grow exasperated and worn, and eventually withdrawn and disengaged.

\section{Correlates of perceived relationship quality}

The current study found that perceived relationship quality was strongly and negatively related to attachment avoidance but was not related to attachment anxiety. Previous research also has found that perceived relationship quality (e.g., commitment, involvement, intimacy, trust, satisfaction, and love) has a strong and robust negative association with attachment avoidance but a weaker and less consistent relationship with attachment anxiety (e.g., Davis et al., 2006; Feeney \& Noller, 1990; Mikulincer, 1998; Noftle \& Shaver, 2006; Ridge \& Feeney, 1998; Shaver \& Brennan, 1992).

Previous studies also suggested that relationship quality might be positively associated with approach goals and negatively associated with avoidance goals (Elliot, Gable, \& Mapes, 2006; Gable, 2006). In contrast, in the current study, perceived relationship quality did not predict approach or avoidance goals with the exception of one weak negative association between the relationship quality and the goal to avoid closeness. Several differences exist between those prior studies and the current study, but I suspect the key difference was that the current study assessed goals specific to one interaction, whereas the prior studies assessed broader goals such as "make some new friends" or "avoid disagreements and conflicts with my friends." Relationship satisfaction 
may have a more direct and robust association with these ongoing projects than with the brief goals assessed in the current study.

\section{Limitations}

The current study is limited in several ways. One limitation is that the participants were a convenience sample of undergraduates rather than a representative sample of the population of romantic partners. Most participants were European Americans fewer than 25 years old in relationships that were fewer than 3 years old; further research may show that variations in age, culture, and relationship length moderate the current findings.

Second, models of motivation emphasize that different behaviors can meet the same goal and different goals can be met by the same behavior (Carver \& Scheier, 1998; Horowitz et al., 2006). For example, a goal to approach closeness can manifest in behaviors as diverse as sending a text message and having sexual intercourse, and conversely, an act of sexual intercourse can reflect goals as diverse as approaching closeness and avoiding assertion. Therefore, since the current study assessed only goals and not behaviors, it does not speak to how the observed variance in interpersonal goals might be reflected in interpersonal behaviors.

A third limitation is the lack of contextual information. (Participants briefly described the interaction, but many of the descriptions were too cryptic to categorize.) Therefore, the current study was unable to test whether certain situations tend to trigger certain goals in individuals with certain attachment styles (cf. Holmes, 2002). Moreover, if individuals with certain attachment styles are more likely to experience certain types of situations, then situations may mediate the effects of attachment styles on interpersonal goals. A previous event-contingent diary study (Pietromonaco \& Barrett, 1997) found that individuals with different attachment styles reported similar numbers of different types of interactions (e.g., interactions high in conflict). Of course, the defining element of an interpersonal situation is the other person. Partners may influence goals directly, by their actions, or indirectly, by priming what goals are salient and what standards are used to evaluate goals and goal progress (Shah, 2005). Gathering information about the partner and the situation would allow future research to tell a more complete story of how the self, the other, and the situation collectively influence everyday interpersonal goals.

A fourth limitation is that the direction of causality is uncertain. For example, a secure attachment style may enhance the desire to be close, or frequently seeking closeness may contribute to the development of a secure attachment style, or a third variable may explain the relationship between secure attachment and seeking closeness. In the current study, age, relationship quality, or relationship length did not explain the links between attachment style and interpersonal goals; however, other variables that the current study did not measure may explain these links.

The event-contingent records used in the present research have both strengths and limitations (Reis \& Gable, 2000). A strength of this study is that instead of recalling or summarizing past interactions, participants describe specific interactions shortly after their occurrence, although it is unknown whether the recorded interactions are representative of all interactions. A related strength is that participants completed the attachment measure in a different situation and on average over a week prior to completing the interaction records, making it unlikely that their responses on the attachment measure influenced their responses on the interaction records. Although the current study cannot determine how quickly and regularly participants completed their records, paper-and-pencil records produce comparable compliance rates, psychometric properties, and results as electronic records that monitor timing and control compliance (Green, Rafaeli, Bolger, Shrout, \& Reis, 2006).

\section{Practical implications}

I hope that the present results will be useful not only to researchers but also to anxious and avoidant individuals seeking to improve their relationships. For example, it may be helpful 
for avoidant individuals and their partners to recognize their automatic goals to avoid closeness and submission and to discuss openly if this might be a problem in certain types of relationship situations. Likewise, it may be helpful for anxious individuals (and their partners) to acknowledge the variability in their goals across interactions. The findings discussed earlier suggest that anxious individuals' instability may arise from a fragile balance between approach and avoidance goals, especially goals to avoid distance and submission. Interventions that help anxious individuals to be less vigilant about avoiding the rejection and humiliation they fear may enable them to focus more fully, consistently, and thus effectively on reinforcing the secure bonds they desire.

\section{Conclusions}

Guided by interpersonal and motivational theory, the current research assessed approach and avoidance communal, uncommunal, agentic, and unagentic goals during everyday interactions between romantic partners. Secure attachment predicted more approach than avoidance goals and especially more approach than avoidance of agency. Avoidant attachment predicted avoiding (and not approaching) communion and submission. Anxious attachment predicted more intense, complex, and variable goals, including focusing less on creating feelings of connection and more on not feeling disconnection or rejection. In sum, attachment style, despite being a global disposition (not specific to any one situation or relationship), explained significant proportions of the variance in momentary relationship goals. I hope these findings will help guide and energize further investigations of the important and intimate relationship between motivation and attachment.

\section{References}

Aiken, L. S., \& West, S. G. (1991). Multiple regression: Testing and interpreting interactions. Newbury Park, CA: Sage.

Ainsworth, M. D., Blehar, M. C., Waters, E., \& Wall, S. (1978). Patterns of attachment. Hillsdale, NJ: Erlbaum.
Anders, S. L., \& Tucker, J. S. (2000). Adult attachment style, interpersonal communication competence, and social support. Personal Relationships, 7, 379-389.

Arriaga, X. B., Reed, J. T., Goodfriend, W., \& Agnew, C. R. (2006). Relationship perceptions and persistence: Do fluctuations in perceived partner commitment undermine dating relationships? Journal of Personality and Social Psychology, 91, 1045-1065

Bartholomew, K., \& Horowitz, L. M. (1991). Attachment styles among young adults: A test of a four-category model. Journal of Personality and Social Psychology, 61, 226-244.

Bartz, J. A., \& Lydon, J. E. (2006). Navigating the interdependence dilemma: Attachment goals and the use of communal norms with potential close others. Journal of Personality and Social Psychology, 91, 77-96.

Bowlby, J. (1973). Attachment and loss: Vol. 2. Separation, anxiety, and anger. New York: Basic Books.

Bowlby, J. (1982). Attachment and loss: Vol. 1. Attachment (2nd ed.). New York: Basic Books.

Brennan, K. A., Clark, C. L., \& Shaver, P. R. (1998). Selfreport measurement of adult attachment: An integrative overview. In J. A. Simpson \& W. S. Rholes (Eds.), Attachment theory and close relationships (pp. 46-76). New York: Guilford.

Brunstein, J. C., Schultheiss, O. C., \& Grassmann, R. (1998). Personal goals and emotional well-being: The moderating role of motive dispositions. Journal of Personality and Social Psychology, 75, 494-508.

Bryk, A. S., Raudenbush, S. W., \& Congdon, R. T. (2005). HLM 6: Hierarchical linear and nonlinear modeling. Chicago: Scientific Software International.

Campbell, L., Simpson, J. A., Boldry, J., \& Kashy, D. A. (2005). Perceptions of conflict and support in romantic relationships: The role of attachment anxiety. Journal of Personality and Social Psychology, 88, 510-531.

Carver, C. S., \& Scheier, M. F. (1998). On the self-regulation of behavior. New York: Cambridge University Press.

Carver, C. S., Sutton, S. K., \& Scheier, M. F. (2000). Action, emotion, and personality: Emerging conceptual integration. Personality and Social Psychology Bulletin, 26, 741-751.

Chen, E. C., \& Mallinckrodt, B. (2002). Attachment, group attraction, and self-other agreement in interpersonal circumplex problems and perceptions of group members. Group Dynamics, 6, 311-324.

Collins, N. L. (1996). Working models of attachment: Implications for explanation, emotion, and behavior. Journal of Personality and Social Psychology, 71, 810-832.

Collins, N. L., \& Feeney, B. C. (2004). Working models of attachment shape perceptions of social support: Evidence from experimental and observational studies. Journal of Personality and Social Psychology, 87, 363-383.

Collins, N. L., \& Read, S. J. (1990). Adult attachment, working models, and relationship quality in dating couples. Journal of Personality and Social Psychology, 58, 644-663.

Corcoran, K., \& Mallinckrodt, B. (2000). Adult attachment, self-efficacy, perspective taking, and conflict resolution. Journal of Counseling \& Development, $78,473-483$.

Creasey, G., \& Hesson-McInnis, M. (2001). Affective responses, cognitive appraisals, and conflict tactics in late adolescent romantic relationships: Associations 
with attachment orientations. Journal of Counseling Psychology, 48, 85-96.

Crowell, J. A., Fraley, R. C., \& Shaver, P. R. (1999). Measurement of individual differences in adolescent and adult attachment. In J. Cassidy \& P. R. Shaver (Eds.), Handbook of attachment: Theory, research, and clinical applications (pp. 434-465). New York: Guilford.

Davila, J., Karney, B. R., \& Bradbury, T. N. (1999). Attachment change processes in the early years of marriage. Journal of Personality and Social Psychology, 76, 783-802.

Davis, D., Shaver, P. R., \& Vernon, M. L. (2004). Attachment style and subjective motivations for sex. Personality and Social Psychology Bulletin, 30, 1076-1090.

Davis, D., Shaver, P. R., Widaman, K. F., Vernon, M. L., Follette, W. C., \& Beitz, K. (2006). "I can't get no satisfaction": Insecure attachment, inhibited sexual communication, and sexual dissatisfaction. Personal Relationships, 13, 465-483.

Diehl, M., Elnick, A. B., Bourbeau, L., \& Labouvie-Vief, G. (1998). Adult attachment styles: Their relations to family context and personality. Journal of Personality and Social Psychology, 74, 1656-1669.

Elliot, A. J., \& Church, M. A. (1997). A hierarchical model of approach and avoidance achievement motivation. Journal of Personality and Social Psychology, 72, 218-232.

Elliot, A. J., Gable, S. L., \& Mapes, R. R. (2006). Approach and avoidance motivation in the social domain. Personality and Social Psychology Bulletin, 32, 378-391.

Elliot, A. J., \& Reis, H. T. (2003). Attachment and exploration in adulthood. Journal of Personality and Social Psychology, 85,317-331.

Feeney, B. C., \& Collins, N. L. (2001). Predictors of caregiving in adult intimate relationships: An attachment theoretical perspective. Journal of Personality and Social Psychology, 80, 972-994.

Feeney, J. A. (2002). Attachment, marital interaction, and relationship satisfaction: A diary study. Personal Relationships, 9, 39-55.

Feeney, J. A., \& Noller, P. (1990). Attachment style as a predictor of adult romantic relationships. Journal of Personality and Social Psychology, 58, 281-291.

Fishbach, A., Friedman, R. S., \& Kruglanski, A. W. (2003). Leading us not unto temptation: Momentary allurements elicit overriding goal activation. Journal of Personality and Social Psychology, 84, 296-309.

Fletcher, G. J. O., Simpson, J. A., \& Thomas, G. (2000). The measurement of perceived relationship quality components: A confirmatory factor analytic approach. Personality and Social Psychology Bulletin, 26, 340-354.

Fraley, R. C., \& Shaver, P. R. (2000). Adult romantic attachment: Theoretical developments, emerging controversies, and unanswered questions. Review of General Psychology, 4, 132-154.

Gable, S. L. (2006). Approach and avoidance social motives and goals. Journal of Personality, 71, 175-222.

Gallo, L. C., Smith, T. W., \& Ruiz, J. M. (2003). An interpersonal analysis of adult attachment style: Circumplex descriptions, recalled developmental experiences, self-representations, and interpersonal functioning in adulthood. Journal of Personality, 71, $141-181$.

Gillath, O., Mikulincer, M., Fitzsimons, G. M., Shaver, P. R., Schachner, D. A., \& Bargh, J. A. (2006). Automatic activation of attachment-related goals. Personality and Social Psychology Bulletin, 32, 1375-1388.

Green, A. S., Rafaeli, E., Bolger, N., Shrout, P. E., \& Reis, H. T. (2006). Paper or plastic? Data equivalence in paper and electronic diaries. Psychological Methods, $11,87-105$.

Greenfield, S., \& Thelen, M. (1997). Validation of the fear of intimacy scale with a lesbian and gay male population. Journal of Personal and Social Relationships, 14, 707-716.

Hazan, C., \& Shaver, P. R. (1987). Romantic love conceptualized as an attachment process. Journal of Personality and Social Psychology, 52, 511-524.

Hazan, C., \& Shaver, P. R. (1994). Attachment as an organizational framework for research on close relationships. Psychological Inquiry, 5, 1-22.

Henderson, A. J. Z., Bartholomew, K., Trinke, S., \& Kwong, M. J. (2005). When loving means hurting: An exploration of attachment and intimate abuse in a community sample. Journal of Family Violence, $20,219-230$

Holmes, J. G. (2002). Interpersonal expectations as the building blocks of social cognition: An interdependence theory analysis. Personal Relationships, 9, $1-26$.

Horowitz, L. M., Wilson, K. R., Turan, B., Zolotsev, P., Constantino, M. J., \& Henderson, L. (2006). How interpersonal motives clarify the meaning of interpersonal behavior: A revised circumplex model. Personality and Social Psychology Review, 10, 67-86.

Kafetsios, K., \& Nezlek, J. B. (2002). Attachment styles in everyday social interaction. European Journal of Social Psychology, 32, 719-735.

Levy, M. B., \& Davis, K. E. (1988). Lovestyles and attachment styles compared: Their relations to each other and to various relationship characteristics. Journal of Social and Personal Relationships, 5, 439-471.

Meyer, B., Olivier, L., \& Roth, D. A. (2005). Please don't leave me! BIS/BAS, attachment styles, and responses to a relationship threat. Personality and Individual Differences, 38, 151-162.

Mikulincer, M. (1998). Attachment working models and the sense of trust: An exploration of interaction goals and affect regulation. Journal of Personality and Social Psychology, 74, 1209-1224.

Mikulincer, M., \& Nachson, O. (1991). Attachment styles and patterns of self-disclosure. Journal of Personality and Social Psychology, 61, 321-331.

Mikulincer, M., \& Shaver, P. R. (2003). The attachment behavioral system in adulthood: Activation, psychodynamics, and interpersonal processes. In M. P. Zanna (Ed.), Advances in experimental social psychology (Vol. 35, pp. 53-152). New York: Academic Press.

Moskowitz, D. S., \& Zuroff, D. C. (2004). Flux, pulse and spin: Dynamic additions to the personality lexicon. Journal of Personality and Social Psychology, 86, 880-893.

Noftle, E. E., \& Shaver, P. R. (2006). Attachment dimensions and the big five personality traits: Associations and comparative ability to predict relationship quality. Journal of Research in Personality, 40, 179-208.

Pietromonaco, P. R., \& Barrett, L. (1997). Working models of attachment and daily social interactions. Journal of Personality and Social Psychology, 73, 1409-1423.

Pietromonaco, P. R., \& Barrett, L. (2006). What can you do for me? Attachment style and motives underlying 
esteem for partners. Journal of Research in Personality, 40, 313-338

Pincus, A. L., \& Gurtman, M. B. (2006). Interpersonal theory and the interpersonal circumplex: Evolving perspectives on normal and abnormal personality. In S. Strack (Ed.), Differentiating normal and abnormal personality (2nd ed., pp. 83-111). New York: Springer.

Pistole, M. C., Clark, E. M., \& Tubbs, A. L., Jr. (1995). Adult attachment and the investment model. Journal of Mental Health Counseling, 17, 199-209.

Reis, H. T., \& Gable, S. L. (2000). Event-sampling and other methods for studying everyday experience. In $\mathrm{H}$. T. Reis \& C. M. Judd (Eds.), Handbook of research methods in social and personality psychology (pp. 190-222). New York: Cambridge University Press.

Ridge, S. R., \& Feeney, J. A. (1998). Relationship history and relationship attitudes in gay males and lesbians: Attachment style and gender differences. Australian and New Zealand Journal of Psychiatry, 32, 848-859.

Rom, E., \& Mikulincer, M. (2003). Attachment theory and group processes: The association between attachment style and group-related representations, goals, memories, and functioning. Journal of Personality and Social Psychology, 84, 1220-1235.
Schachner, D. A., \& Shaver, P. R. (2004). Attachment dimensions and motives for sex. Personal Relationships, 11, 179-195.

Shah, J. (2005). Automatic pursuit and management of goals. Current Directions in Psychological Science, $14,10-13$

Shaver, P. R., \& Brennan, K. A. (1992). Attachment styles and the "Big Five" personality traits: Their connections with each other and with romantic relationship outcomes. Personality and Social Psychology Bulletin, 18, 536-545.

Shaver, P. R., Papalia, D., Clark, C. L., Koski, L. R., Tidwell, M. C., \& Nalbone, D. (1996). Androgyny and attachment security: Two related models of optimal personality. Personality and Social Psychology Bulletin, 22, 582-597.

Simpson, J. A., \& Rholes, W. S. (1998). Attachment in adulthood. In J. A. Simpson \& W. S. Rholes (Eds.), Attachment theory and close relationships (pp. 3-21). New York: Guilford.

Tidwell, M. O., Reis, H. T., \& Shaver, P. R. (1996). Attachment, attractiveness, and social interaction: A diary study. Journal of Personality and Social Psychology, 71, 729-745. 